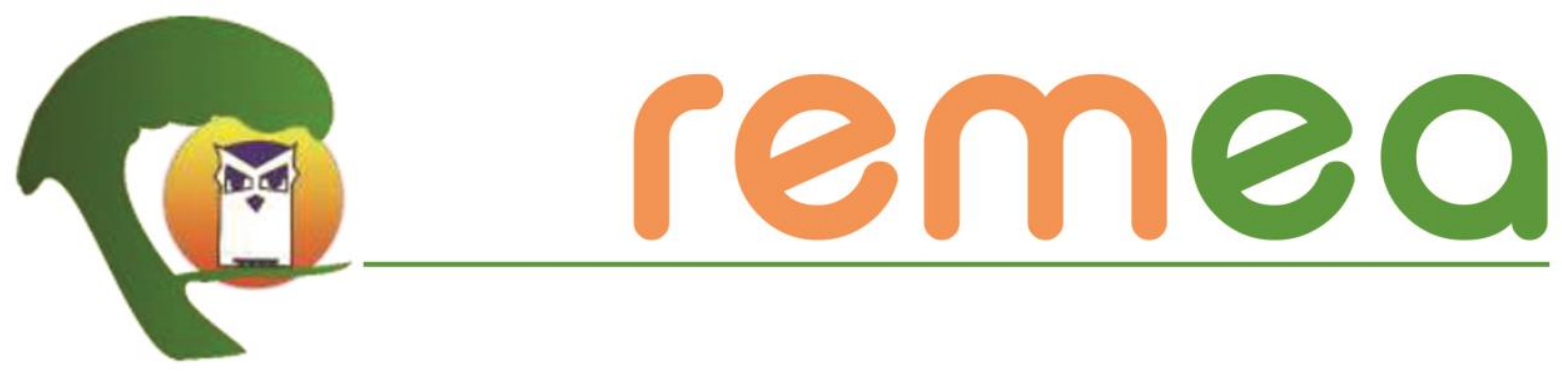

\title{
A Temática Ambiental e o Processo Educativo nas pesquisas do grupo Ágora: uma trajetória de três décadas
}

\author{
Maria Bernadete Sarti Silva Carvalho ${ }^{1}$ \\ Universidade Estadual Paulista Júlio de Mesquita Filho, campus Rio Claro \\ ORCID: https://orcid.org/0000-0002-5295-572
}

Resumo: O texto traz um relato da trajetória e apresenta o panorama da produção do grupo de pesquisa Ágora, em três décadas de participação no debate sobre significados e sentidos construídos sobre a relação entre o processo educativo e a temática ambiental. Foram produzidos estudos sobre práticas pedagógicas, concepções e representações de natureza e meio ambiente, bem como análises e proposições no subcampo das políticas públicas para a EA. O grupo tem desenvolvido projetos de pesquisa do tipo Estado da Arte, analisando a produção acadêmica em Educação Ambiental (EA). Os trabalhos têm enfatizado o significado do processo educativo como prática social, e a Educação Ambiental como prática de construção de sociedades democráticas. As análises da produção de pesquisa em EA denotam a centralidade da dimensão política nas práticas pedagógicas e nas práticas de produção de conhecimentos no campo.

Palavras-chave: Grupo de Pesquisa; Educação ambiental; dimensão política.

\section{El tema ambiental y el proceso educativo en la investigación del Grupo Ágora: una trayectoria de tres décadas}

Resumen: El texto relata la trayectoria y presenta un panorama de la producción del grupo de investigación Ágora, en tres décadas de participación en el debate sobre significados construidos sobre la relación entre el proceso educativo y el tema ambiental. Se produjeron estudios sobre prácticas pedagógicas, concepciones y representaciones de la naturaleza y el medio ambiente, y también análisis y propuestas en el subcampo de las políticas públicas de EA. El grupo ha desarrollado proyectos de investigación del tipo Estado del Arte, analizando la producción académica en Educación Ambiental (EE). Los trabajos han enfatizado el significado del proceso educativo como práctica social y la Educación Ambiental como práctica para la construcción de sociedades democráticas. Los análisis de la producción de investigación en EA denotan la centralidad de la dimensión política en las prácticas pedagógicas y las prácticas de producción de conocimiento en el campo.

Palabras-clave: Grupo de investigación; Educación ambiental; dimensión política.

The Environmental Thematic and the Educational Process in the Ágora group's research: a trajectory of three decades 1 Doutora em Geografia, professora no Departamento de Educação, Unesp Rio Claro. E-mail:
maria.carvalho@unesp.br 
Abstract: The text reports the trajectory and presents an overview of the Ágora Research Group productions, in three decades of participation in the debate on meanings built on the relationship between the educational process and the environmental theme. Studies were produced on pedagogical practices, conceptions and representations of nature and the environment, as well as analyzes and propositions in the subfield of public policies for EE. The group has developed State of the Art research projects, analyzing academic production in Environmental Education (EE). The works have emphasized the meaning of the educational process as a social practice, and Environmental Education as a practice for building democratic societies. Analyzes of research production in EE denote the centrality of the political dimension in pedagogical practices and knowledge production practices in the field.

Keywords: Research Group; Environmental education; political dimension.

\section{Introdução}

Tendo em vista o panorama mundial de preocupações com o meio ambiente em virtude do que tem sido considerada uma crise socioambiental, podendo resultar em um colapso ambiental (LEFF, 2001; MARQUES, 2015), surge e se amplifica a necessidade de impulsionar processos educativos e ações sociais, além da proposição de políticas públicas, que levem a sociedade a repensar os atuais modelos de interação sociedade e natureza, assim como propor alternativas a eles.

O grupo de pesquisa que aqui apresentamos tem se dedicado à produção de conhecimentos sobre significados e sentidos que temos atribuído ao processo educativo, visto como uma das práticas sociais que nos ajudam a problematizar os processos de relação sociedade e natureza. Suas atividades se iniciaram no ano de 1992 , tendo como registro no diretório do CNPq a denominação "A temática ambiental e o processo educativo".

Ao longo de suas três décadas de atividades, o grupo Ágora, ou "A temática ambiental e o processo educativo", produziu um conjunto de trabalhos dos mais diferentes níveis de pesquisa - de Trabalhos de Conclusão de Curso a teses de Doutorados - e tem procurado participar dessa rede infinita de produção de sentidos sobre as ações educativas desenvolvidas em espaços escolares e não escolares de educação, relacionadas à temática ambiental, colocando-se, teórica e metodologicamente, sempre num caminho de busca mediante as inquietações e problemas socioambientais colocados pelo contexto histórico, político e social.

Neste trabalho temos como propósito, além de apresentar um panorama geral e as principais temáticas abordadas na produção de pesquisas pelo grupo, produzir um movimento descritivo-analítico, em que seja possível reconhecer o processo de participação 
do grupo no debate sobre a EA e na construção de significados e sentidos sobre a relação entre o processo educativo e a temática ambiental.

\section{Histórico de uma trajetória}

Historicamente, o grupo se constituiu a partir de trabalhos vinculados a um programa da Pró-reitoria de graduação da Unesp, denominado Núcleos de Ensino, cuja finalidade é aproximar a Universidade da rede pública de educação básica, em seus diferentes níveis, pela realização de projetos que abordam diferentes aspectos do processo educativo. No caso do grupo de pesquisa em tela, a proposta envolveu a temática ambiental, numa abordagem interdisciplinar, que acabou se desdobrando em propostas de pesquisa que foram realizadas com apoio de órgãos de fomento à pesquisa, conforme descrito por BONOTTO et al. (2009):

Dentre os primeiros projetos de pesquisa propostos pelo grupo, dois deles, desenvolvidos no período de 1995 a 1997, merecem destaque. Um desses projetos, "A temática ambiental e a produção de material didático: uma proposta interdisciplinar", recebeu apoio do extinto Subprograma para o ensino das Ciências (SPEC), vinculado ao Programa de Desenvolvimento Científico e Tecnológico (PADCT). Este projeto que envolvia as áreas de ciências da natureza, de matemática e de geografia, contou com a participação de nove professores da rede pública, sendo uma de cada uma das áreas mencionadas e nove alunos, três de cada um dos cursos de licenciatura referidos acima. Todos os professores envolvidos no projeto, assim como os alunos, receberam bolsas de auxílio à pesquisa pelo trabalho desenvolvido (BONOTTO et al., 2009, p. 123-124).

Além dessas iniciativas, mais voltadas ao ensino de graduação e à melhoria da educação básica, o grupo buscou se fortalecer como linha de pesquisa, propondo um curso de Especialização Latu Sensu, que foi oferecido no ano de 2000 com o apoio dos Departamentos de Educação, Ecologia e Educação Física da Unesp de Rio Claro. Essa experiência e as de outros grupos de pesquisa, vinculados ao Departamento de Educação, e os seus desdobramentos como pesquisa acadêmica resultaram na proposição, em conjunto com outros pesquisadores do mencionado departamento, de um programa de pósgraduação em Educação stricto senso, que teve início em 2003. No âmbito do programa de Pós-graduação em Educação, o grupo de pesquisa passa a se responsabilizar e coordenar a linha de pesquisa em Educação Ambiental. 
Ao longo do tempo, é importante destacar as iniciativas do grupo de pesquisadores, que, ao se envolverem com outras instituições e grupos de pesquisa, produziram contribuições para o campo da Educação Ambiental (EA). Entre outras parcerias estabelecidas, no período de 2002 a 2003 o grupo integrou o Programa de Cooperação entre a União Europeia e América Latina (ALFA) e participou do projeto "Rede Ambientalização Curricular dos Estudos Superiores (Rede ACES), em conjunto com universidades brasileiras, latino-americanas e europeias. Sobre esse trabalho, Oliveira et al. (2009) afirmam:

\begin{abstract}
No plano internacional, merece destaque o projeto da Rede ACES Ambientalização Curricular do Ensino Superior, constituída por 11 universidades de 7 diferentes países, entre as quais 3 IES públicas brasileiras. Uma avaliação do trabalho desenvolvido no âmbito desta rede, no período de 2002 a 2004, pode ser encontrada em Freitas e Oliveira (2004), cujo artigo traz uma leitura dos percursos diferenciados de ambientalização que cada instituição envolvida escolheu para trilhar e dos indicadores da produção de conhecimento para a área em questão, ou seja, da ambientalização curricular no ensino superior (OLIVEIRA et al., 2009, p. 6).
\end{abstract}

Com parte do seu histórico de constituição, trazemos como uma das mais importantes iniciativas do grupo de pesquisa, em colaboração com grupos da Universidade de São Paulo (USP - Ribeirão Preto) e da Universidade Federal de São Carlos (UFSCar) a organização dos Encontros de Pesquisa em Educação Ambiental (EPEA). Inicialmente, para sua realização, os encontros eram sediados em alternância entre os municípios de localização das universidades envolvidas (Rio Claro, Ribeirão Preto e São Carlos). A partir de 2013, com decisão discutida entre líderes de grupos de pesquisa, teve início o ciclo de edições nacionais do EPEA, ampliando seu alcance como evento organizado por grupos de pesquisa em EA e possibilitando o fortalecimento das discussões entre os grupos e da produção de conhecimentos no campo, conforme consta na página oficial que publica os Anais do evento (http://www.epea.tmp.br):

[...] Pela primeira vez, o evento foi sediado no Rio de Janeiro, realizado por grupos de pesquisa de IES do Rio de Janeiro (Universidade Federal Rural do Rio de Janeiro - UFRRJ, Universidade Federal do Rio de Janeiro - UFRJ e Universidade do Rio de Janeiro - UNIRIO), iniciando uma nova fase, para além do Estado de São Paulo. A realização deste evento no Estado do Rio de Janeiro favorece a produção e o surgimento de novos núcleos de produção acadêmica, gerando uma expertise local, favorável à promoção da sustentabilidade socioambiental do desenvolvimento do Estado do Rio de Janeiro, propondo o tema "A avaliação da 
década da Educação para o Desenvolvimento Sustentável e perspectivas futuras" (FERNANDES, 2017, s.p. grifos nossos).

[...] O acontecimento deste evento em Juiz de Fora, no estado de Minas Gerais, confirma essa territorialidade. Capitaneado pelo GEA - Grupo de Pesquisa em Educação Ambiental da Universidade Federal de Juiz de Fora, em parceria com os grupos de pesquisa de IES do Rio de Janeiro (Universidade Federal Rural do Rio de Janeiro - UFRRJ, Universidade Federal do Rio de Janeiro - UFRJ e Universidade do Rio de Janeiro - UNIRIO), o Encontro favorece a produção e o surgimento de novos núcleos de pesquisa acadêmica em nosso estado, gerando uma expertise local, favorável ao fortalecimento de grupos de pesquisa e à promoção da sustentabilidade socioambiental" (FERNANDES; PINTO; SOBRAL, 2017, s.p. grifos nossos).

[...] A educação ambiental tem sido centro de discussões em programas de pósgraduação diante da sua emergência em tratar as questões socioambientais na formação ambiental dos sujeitos. O X EPEA, realizado em São Cristóvão, no campus da Universidade Federal de Sergipe, sob o apoio do Programa de Pós-Graduação em Educação e do Grupo de Estudos e Pesquisa em Educação Ambiental de Sergipe (GEPEASE), tomou como foco a relação do atual cenário político, social e cultural brasileiro, considerando as questões contemporâneas que atravessam tais relações e discutindo sobre o papel do EPEA nos avanços das pesquisas em EA nos últimos 20 anos" (COMISSÃO ORGANIZADORA, 2019, s.p, grifos nossos).

A partir dessa iniciativa de envolvimento dos grupos de pesquisa interessados na organização e continuidade desse evento, diferentes grupos de pesquisa, por meio da Rede EPEA têm, colaborativamente e em parceria, mantido e garantido a organização desse espaço para divulgação, discussão e fortalecimento da pesquisa em EA no Brasil.

No mesmo período em que se iniciaram os Encontros de Pesquisa em Educação Ambiental (2001), o grupo de pesquisa participou ativamente das discussões sobre a constituição do GT-22 de Educação Ambiental, junto à Associação Nacional de Pósgraduação em Educação (ANPEd). Um dos espaços de articulação foi o I Encontro de Pesquisa em Educação Ambiental, ocorrido em Rio Claro - SP, conforme consta no relato produzido em 31 de julho de 2001, disponível na ANPEd, e que segue, em parte, transcrito neste trabalho:

REUNIÃO DE ARTICULAÇÃO DE CRIAÇÃO DO GE/EA NA ANPED O grupo de pesquisadores/as da área de EA interessados/as na articulação para a consolidação de um espaço para a EA na ANPED, reuniu-se no EPEA - Encontro Pesquisa em EA realizado em Rio Claro, S.P., no dia 30 de julho p.p., e a partir de intensa troca de ideias, deliberou os seguintes encaminhamentos:

- Sugerir a consolidação do EPEA a partir de seu desdobramento em novos encontros com uma periodicidade regular. 
- Ocupação de um espaço formal na programação paralela da 24a Reunião Anual da ANPED (7 a 11 de outubro de 2001, em Caxambú/MG), para continuação das discussões que vem ocorrendo desde a 22a RA, em 1999 sobre a criação de um GE/EA.

- Esforço coletivo para que tenhamos uma presença de um número significativo de pessoas vinculadas à EA nesse espaço articulado na ANPED.

Aqui, cabe uma observação importante sobre a denominação que aparece no GT-22 como sendo "Ágora: Grupo de Estudos e Pesquisas em Educação Ambiental - Unesp/SP". No diretório de grupos de pesquisa do CNPq permanece a denominação do grupo como "A temática ambiental e o processo educativo". A denominação Ágora surgiu após a construção de uma dependência própria do grupo de pesquisa, financiada pela FAPESP, a partir de um projeto de pesquisa para melhoria da escola pública. O espaço se constituiu como sendo de diálogo e produção de conhecimentos e, em 2008, foi nomeado Ágora. Permanece tendo como foco temático para suas pesquisas "A temática ambiental e o processo educativo", como consta no CNPq.

Decorrente desse processo, e tendo como preocupação a divulgação do conhecimento no campo, produzido pelos pesquisadores em EA em todo o Brasil, o grupo, em parceria com os demais grupos promotores do EPEA, idealizou e lançou, em 2006, o primeiro número do periódico Pesquisa em Educação Ambiental, o qual se consolidou no cenário de publicações científicas do país, e já está no seu volume 16, completando quinze anos de edições ininterruptas. A revista é reconhecida nacionalmente, recebendo artigos de todo o Brasil em fluxo contínuo, e a publicação de dois números por ano, com o propósito de:

[...] contribuir para a consolidação e fortalecimento desse campo de pesquisa. Publica artigos originais e inéditos resultantes de pesquisas empíricas e/ou estudos teóricos produzidos por autores brasileiros e estrangeiros, possibilitando reflexões e o aprofundamento teórico e metodológico desse campo do conhecimento e das práticas de pesquisa e práticas pedagógicas em Educação Ambiental (REVPEA, s.d., s.p.).

Após esse panorama inicial da movimentação do grupo pelos espaços institucionais (graduação e pós-graduação), a criação de novos espaços para desenvolver e divulgar o resultado de investigações no campo da EA (o EPEA e a revista Pesquisa em Educação Ambiental) e a participação em redes de comunicação entre grupos de pesquisa em EA, é 
interessante apresentar, no sentido de sistematizar a produção das pesquisas pelo grupo, para reconhecer nela os processos de investigação, individuais e coletivos, que têm sido desenvolvidos com o intuito de produção de conhecimentos e significados sobre a EA no Brasil, a partir de proposições teóricas e metodológicas de base crítica.

\section{A produção de pesquisas e suas principais temáticas}

Nesta seção, trazemos os dados da produção de pesquisas até o ano de 2021, desenvolvidas sob orientação de pesquisadores do grupo Ágora, considerando todos os níveis em que ocorrem, quais sejam, Trabalhos de Conclusão de Curso (TCC) e Iniciação Científica (IC), Dissertações de Mestrado e Teses de Doutorado. Na Figura 1 trazemos a totalidade dessa produção, sua evolução temporal e a distribuição de acordo com os diferentes níveis de orientação das pesquisas.

O grupo de pesquisadores, na totalidade, orientou 191 trabalhos que exploram a relação entre educação e a temática ambiental ${ }^{2}$. Verificamos que, ao longo de três décadas, foram 54 orientações de trabalhos em nível de graduação ( $28,2 \%$ do total). Sobre essa produção, registramos que o Ágora manteve, por um longo período (2005-2019), um espaço de estudo e discussões sobre a temática ambiental e a educação ambiental, denominado Grupo da Floresta, criado especialmente para alunos da graduação dos diferentes cursos oferecidos pela Unesp de Rio Claro, preparando-os para a pesquisa e oferecendo orientação para os seus trabalhos de TCC e de IC.

\footnotetext{
${ }^{2}$ Essa totalização pode ter variação para mais, em virtude de trabalhos de pesquisa que foram registrados na Plataforma Lattes como sendo "orientações de outra natureza"; por exemplo, trabalhos vinculados a projetos de extensão e à Prática como Componente Curricular, que, no Curso de Ciências Biológicas da Unesp de Rio Claro, se dá em forma de uma pesquisa em Educação. Muitos alunos desenvolvem suas pesquisas com o tema Educação Ambiental.
} 
Figura I: Distribuição temporal da produção do Grupo Ágora, por níveis de pesquisa (1991-2021)

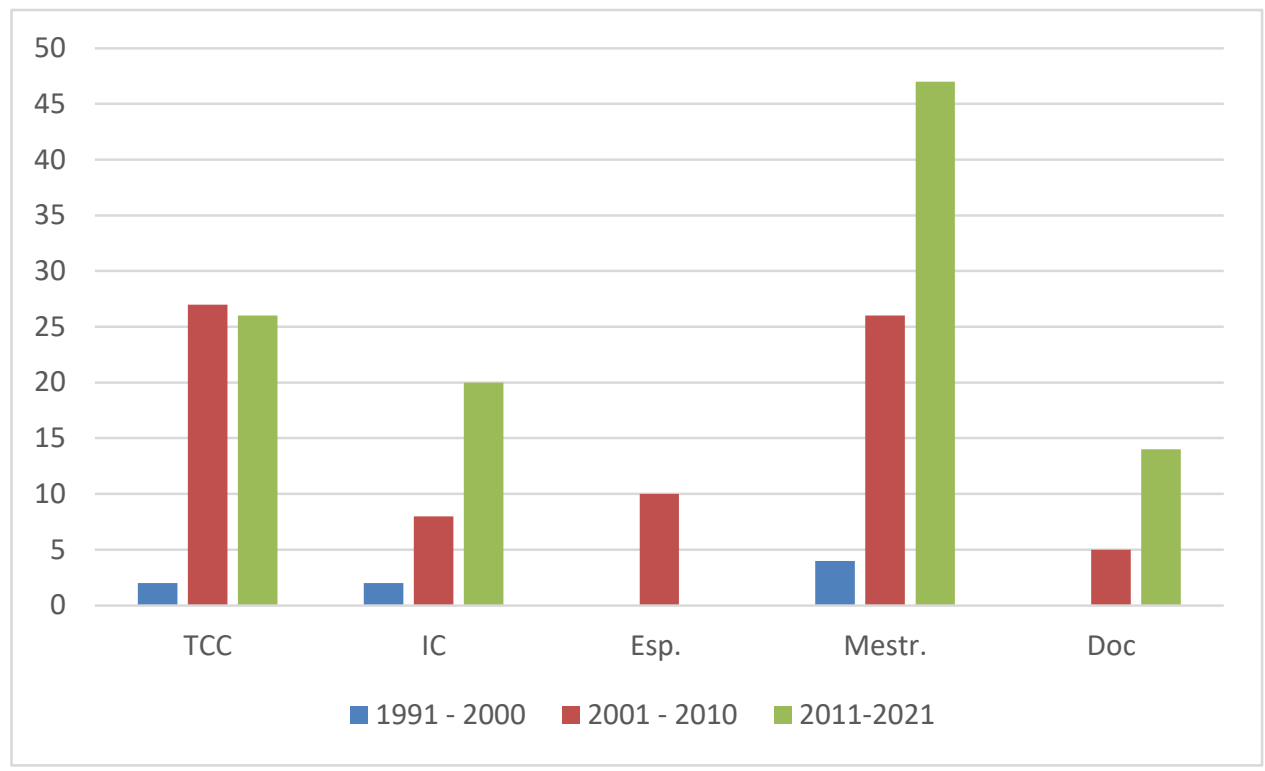

Fonte: elaborada pela autora com base em dados obtidos na Plataforma Lattes

Na Pós-graduação os trabalhos de mestrado e doutorado, que se iniciam na segunda década de atividades do grupo, com a primeira defesa no ano de 2002, a produção apresenta uma evolução nos dois níveis, de uma década para outra. Esse dado pode ser interpretado como um indicativo de fortalecimento não só do Programa de Pós-graduação em Educação, mas também da linha de pesquisa, pois, ao longo dos anos, o interesse dos que procuram pelo programa e pela linha tem se mantido, com ingresso de mestrandos e doutorandos de diferentes regiões do estado de São Paulo e do Brasil, com formação nos mais diversos campos de conhecimento.

Para uma análise mais detalhada da produção total buscamos identificar as principais temáticas presentes nos trabalhos já desenvolvidos, o que nos levou a compor três grandes conjuntos, a saber:

Temáticas de natureza pedagógica: trabalhos que investigaram projetos, programas, currículos em EA escolar, atividades e projetos em EA não escolar, processos e métodos de ensino e aprendizagem, recursos didáticos e trabalho e formação de professores e agentes de EA. 
Temáticas de natureza sociopolítica: trabalhos que investigaram a comunicação social e suas relações com EA, as políticas públicas em EA, a organização da instituição escolar, as ações de organizações governamentais e não governamentais e as relativas aos movimentos sociais/ambientalistas, além de pesquisas sobre temas controversos que têm repercussão importante na sociedade ou em segmentos sociais específicos.

Temáticas que exploram fundamentos teóricos metodológicos e o sentido da EA: trabalhos que investigam concepções/representações e processos cognitivos do formador em EA (professores, agentes e profissionais que atuam em EA), concepções/representações e processos cognitivos do aprendiz em EA (alunos ou populações de determinada região); aspectos filosóficos, epistemológicos, metodológicos ou históricos em EA ou para o tratamento das questões ambientais.

Verificamos, por meio de procedimentos de busca e de leitura de resumos, que predominam na produção do grupo as pesquisas que se voltam para as questões de natureza pedagógica em espaços escolares e não escolares de educação, representando $54,9 \%$ do total. Nesse conjunto são analisadas, principalmente as práticas pedagógicas para a EA, em diferentes níveis de ensino e sistemas educativos, além de investigar a formação docente, inicial e continuada, considerada fundamental para a melhoria dos processos educativos. Esse volume de trabalhos traz discussões e indica os limites e os desafios do trabalho docente em EA, oferecendo subsídios teóricos e práticos para qualificar essa atuação.

O segundo e terceiro conjuntos de temáticas identificadas nos trabalhos - as de natureza sociopolítica e os que se preocupam com a produção dos conhecimentos e os fundamentos para a pesquisa no campo ou que investigam os sentidos que temos produzido sobre a EA - representam, respectivamente, $28,7 \%$ e $16,4 \%$ da produção do grupo. Esses trabalhos, como parte de um movimento que se dá no campo da pesquisa em EA, contribuem para produzir novos significados e sentidos para a relação entre os seres humanos e a natureza, e que podem alicerçar as propostas de ações educativas que sejam transformadoras da realidade ambiental em diferentes escalas, do local ao global.

Sobre a contribuição desses estudos, no sentido de inaugurar novos caminhos para a EA numa perspectiva crítica, trazemos os dizeres de Carvalho (2020, p. 47), quando, ao se 
referir à oposição que construímos historicamente entre EA conservadora e uma EA crítica, afirma que "[...] ainda que essa oposição possa ter tido um sentido nos anos 1970, na afirmação de uma EA crítica, considero que faz algum tempo essa oposição deixou de trazer qualquer produtividade para a EA."

Assim como a autora, entendemos que não temos, necessariamente, que nos opor aos pragmatismos e conservadorismos, mas que é preciso mergulhar criticamente na produção das pesquisas e entender o que emerge delas para constituir um novo caminho de significação e de sentidos para as ações em EA. Assim, o grupo Ágora tem realizado esforços para, a partir de estudos que se voltam para as concepções/compreensões em EA e seus fundamentos no tratamento das questões ambientais, fomentar novas formas de pensar e fazer a EA, entendida como prática social educativa. Tal esforço tem envolvido, frequentemente, um diálogo de saberes (LEFF, 2009, p. 19) que se produz no encontro de identidades, necessitando investigar diferentes atores, inclusive coletividades, para entender as demandas e urgências ambientais que se apresentam.

Ao nos voltarmos para os projetos de pesquisa desenvolvidos pelos pesquisadores do grupo, podemos identificar a preocupação com o processo educativo, tanto no contexto escolar como o não escolar, com as práticas pedagógicas, com a dimensão política e com a produção de conhecimentos em EA a partir de seus fundamentos filosóficos e epistemológicos, além do envolvimento coletivo com a análise da produção acadêmica (teses e dissertações). A seguir, elencamos os principais projetos atualmente desenvolvidos pelo grupo.

1- Articulações entre as áreas da Educação Ambiental e da Educação em Ciências: significados produzidos por pesquisadores em teses e dissertações do campo da educação ambiental.

2- Educação Ambiental e formação para a cidadania: tendências, debates e práticas educativas.

3- Relatos de Pesquisa em Educação Ambiental: produção de sentidos sobre dimensões políticas do processo educativo.

4- Processo de consolidação da Educação Ambiental na sociedade brasileira contemporânea: a contribuição da política pública de Educação Ambiental. 
5- A natureza no pensamento filosófico: a possibilidade de uma Filosofia da Natureza?

6- Estado da Arte da Pesquisa em Educação Ambiental no Brasil: análise de dissertações e teses - 1981-2020 (Projeto EArte) ${ }^{3}$

Ainda, buscando apresentar e caracterizar o trabalho do grupo de pesquisa, é importante identificar, na proposição dos projetos, um fio condutor para as pesquisas e orientações. Esse fio condutor busca explorar três dimensões consideradas fundamentais para a temática ambiental e o processo educativo: a dimensão relacionada com a natureza dos conhecimentos, a dimensão axiológica de nossa existência (valores éticos e estéticos) e a dimensão política do processo educativo em geral, e da educação ambiental, em particular. O trabalho com as três dimensões propostas por Carvalho (2006) é assumido pelo grupo como uma das perspectivas que, no conjunto de outros estudos e argumentações de natureza teórica e prática, vem propor uma Educação Ambiental crítica, ou seja, pensada como uma práxis transformadora.

O movimento do grupo e os estudos até aqui desenvolvidos demonstram que a dimensão política se coloca como um dos pilares para a elaboração das pesquisas do grupo, de forma crítica e consequente. Para Carvalho (2006, p. 26), “a dimensão política como central na caracterização do processo educativo em geral e para os processos de educação ambiental em particular", sendo que as demais dimensões são articuladas à dimensão política como sendo de complementaridade e reciprocidade. Sobre essa proposta, o autor destaca que essa é uma articulação de natureza dialética, envolvendo teoria e prática, e constituída de forma intencional para cumprir a perspectiva crítica e emancipadora da educação, sendo assim transformadora.

A respeito da dimensão política dos processos educativos, e considerando que o grupo Ágora se consolida na busca por produzir conhecimentos sobre significados e sentidos que temos atribuído a esses processos, visto como uma das práticas sociais que nos ajudam a problematizar os processos de relação sociedade e natureza, concordamos com Carvalho (2015, p. 150) quando afirma:

\footnotetext{
${ }^{3}$ Cinco dos pesquisadores do grupo participam do Projeto EArte, propondo-se, nos projetos individuais de orientação de mestrados e doutorados, a analisar teses e dissertações em EA, além da participação no projeto interinstitucional em seus objetivos gerais e específicos.
} 
Parece-me essencial considerar a historicidade dos conceitos de cidadania e de participação social e as reais condições para que as práticas educativas que temos proposto, relacionadas com a temática ambiental, possam produzir efeitos de transformação no sentido de construção do mundo novo ao qual tanto nos referimos. Pensar em propostas educacionais criativas, novas, que nos ajudem a inventar o não pensado. Pensar o mundo ainda não inventado é um exercício necessário.

Posta a centralidade da dimensão política nas pesquisas em EA, mesmo quando elas se voltam para aspectos pedagógicos ou epistemológicos, situamos, entre os inúmeros trabalhos produzidos com esse foco e, particularmente, na análise de políticas públicas para a EA, o estudo desenvolvido por Lopes (2021). A dissertação de mestrado, defendida recentemente, pode ser tomada como um exemplo, quando, ao analisar quatro das Salas Verdes existentes no estado de São Paulo, desvelando, na forma de implantação e de gestão e nas ações propostas em seus Projetos Políticos Pedagógicos, entre outros aspectos, se os projetos analisados estão ou não atendendo à Política Nacional de Educação Ambiental (PNEA) e quais princípios da política nacional estão sendo privilegiados ${ }^{4}$. Os resultados, embora se refiram ao estado de São Paulo, permitem concluir que o projeto do Ministério do Meio Ambiente (MMA), como parte de uma política pública para a $E A$, deve ser aperfeiçoado e divulgado, pois, pelas experiências analisadas na pesquisa, o projeto Salas Verdes tem potencial para colocar em prática os princípios e diretrizes da PNEA.

Cabe destacar que, dos trabalhos até aqui produzidos pelo Ágora, onze $(5,7 \%)$ deles se voltaram para o estudo de políticas públicas especificamente, denotando, por diferentes caminhos de investigação e análise, o significado social e a importância delas para produzir mudanças no sentido da sustentabilidade ambiental planetária. Esta nossa compreensão, como pesquisadora e como grupo de pesquisa, é corroborada por outros pesquisadores e produz iniciativas fundamentais em nosso país, em meio a um processo político de extrema instabilidade, principalmente no tratamento das questões ambientais. A exemplo disso tivemos, recentemente, a construção da Plataforma Brasileira de Monitoramento e Avaliação de Políticas Públicas de Educação Ambiental para Sociedades Sustentáveis,

\footnotetext{
${ }^{4}$ A pesquisa mencionada está relatada em um dos trabalhos que compõem o dossiê Movimentos Teóricos e Metodológicos no Grupo de Trabalho 22 Educação Ambiental da ANPED.
} 
realizado pela Secretaria Executiva da Articulação Nacional de Políticas Públicas de Educação Ambiental (ANPPEA) ${ }^{5}$.

Em publicação sobre essa iniciativa, escrevem os pesquisadores responsáveis:

Aqui são reveladas histórias, análises, intervenções, utopias, necessidades, expectativas, diversidade, caminhadas longas ou iniciantes, - que avançaram ou ainda avançam na formulação, execução, monitoramento e avaliação de políticas públicas de Educação Ambiental-, demonstrando o quanto nós educadores e educadoras ambientais, o quanto as ações e políticas públicas desenvolvidas neste país são 'mandacarus' neste sistema opressor, injusto e desigual. A partir da materialidade e da complexidade dos indicadores encontramos no Brasil muitos 'mandacarus', alguns estão presentes nesta publicação, transparecendo seus espinhos e sua suculência, suas forças e suas flores, suas terras rasas e áridas à espera de regadores e nutrientes que lhes permitam continuar de pé e existir (RAYMUNDO et al., 2019, p. 21).

Para concluir este esforço descritivo-analítico que empreendemos, referente ao grupo de pesquisa Ágora, na próxima seção vamos particularizar o projeto coletivo e de caráter interinstitucional, conhecido como Projeto EArte, em sua proposta de compreender o campo da pesquisa em EA em diferentes regiões do território brasileiro e, mais recentemente, em diferentes países onde há grupos de pesquisa que atuam com preocupações da mesma natureza.

\section{A produção do grupo no âmbito do Projeto EArte}

No conjunto das atividades do grupo Ágora, gostaríamos de destacar a contribuição do Earte, por meio do qual o grupo tem desenvolvido projetos de pesquisa do tipo estado da arte, dedicando-se a analisar a produção acadêmica, produzindo estudos panorâmicos e analíticos sobre o campo da pesquisa em Educação Ambiental no Brasil.

Como continuidade a um projeto inicialmente liderado pelo Prof. Hilário Fracalanza, ${ }^{6}$ da Faculdade de Educação da Unicamp, a partir de 2008, passou a contar com a participação

\footnotetext{
${ }^{5}$ A ANPPEA é composta pelo Laboratório de Educação e Política Ambiental - Oca da Escola Superior de Agricultura Luiz de Queiroz da Universidade de São Paulo (ESALO/USP); Laboratório de Análises e Desenvolvimento de Indicadores de Sustentabilidade do Centro de Ciência do Sistema Terrestre do Instituto Nacional de Pesquisas Espaciais (LADIS/CCST/INPE) e Fundo Brasileiro de Educação Ambiental (FunBEA). https://www.monitoraea.org.br/

${ }^{6}$ Referência na pesquisa sobre ensino de Ciências, Prof. Hilário Fracalanza idealizou e coordenou o projeto de Pesquisa "O que sabemos sobre Educação Ambiental no Brasil: análise da produção acadêmica (dissertações e teses)", desenvolvido pelo Grupo Formar, por meio do Centro de Documentação da Faculdade de Educação da UNICAMP - CEDOC, do qual se originou o Projeto EArte. Faleceu em janeiro de 2009, deixando importante legado de estudos e pesquisas.
} 
de pesquisadores de Universidades Estaduais de São Paulo (UNESP - Rio Claro, UNICAMP e USP - Ribeirão Preto) e da UFSCar. Assim, a partir desse ano, configurou-se como um projeto de caráter interinstitucional que, intitulado "Estado da Arte em Educação Ambiental no Brasil", passou, após a divulgação do Banco de Dados, a ser conhecido como Projeto EArte.

A pesquisa, ao longo desse período de treze anos, obteve financiamento, pela participação em dois editais Universal do Conselho Nacional de Desenvolvimento Científico e Tecnológico (CNPq), cujos recursos foram fundamentais para desenvolver e tornar público o Banco de Dados do EArte, assim como para financiar alunos em seus projetos de pesquisa.

Atualmente, em uma nova fase de trabalho e com financiamento da FAPESP, o projeto intitulado "Estado da Arte da Pesquisa em Educação Ambiental no Brasil: análise de dissertações e teses - 1981-2020 (Projeto EArte)", tem como objetivos:

- Identificar tendências da produção das pesquisas em EA, desenvolvidas por alunos de pósgraduação ao longo dos anos no Brasil, sistematizando aspectos significativos dessa produção, tanto do ponto de vista quantitativo quanto qualitativo, construindo quadros descritivos e panorâmicos dessa produção; e

- Desenvolver, a partir de focos de interesse dos docentes e das instituições envolvidas no projeto e de alunos de doutorado, estudos analíticos das teses e dissertações (metaanálises), procurando explorar perspectivas variadas das pesquisas, quer seja do ponto de vista dos pressupostos teórico-metodológicos que vêm orientando as pesquisas do campo, quer seja das tendências temáticas e político-pedagógicas enfatizadas nos trabalhos de pesquisa em EA no país.

No desenvolvimento do Projeto EArte, os estudos exploram as teses e dissertações vistas como gêneros discursivos, ou seja, como um "tipo específico de gênero textual, constituído pelos gêneros acadêmicos, que incluem relatos de pesquisa, ensaios teóricos, teses de doutorado, dissertações de mestrado, resenhas e resumos apresentados em reuniões científicas" (CARVALHO, 2015, p. 43). Nesse sentido, o da análise discursiva, alguns dos pesquisadores do grupo têm se aproximado e encontrado apoio nos escritos de Bakhtin (2010) e, do ponto de vista metodológico, a produção de sentidos aparece como um caminho promissor para produzir uma análise fundamentada sobre como temos nos relacionado com a natureza e produzido discursos sobre essa relação e sobre a própria 
educação ambiental. Em outras palavras, segundo Carvalho $(2015$, p. 17) "nossos textos de pesquisa, para além de um relato objetivo dos processos educativos em relação à temática ambiental, contribuem, decisivamente, com seus processos discursivos para a construção e atribuição de sentidos sobre essa realidade."

\section{Considerações finais}

Após apresentarmos o histórico da constituição do grupo de pesquisa Ágora e o conjunto da sua produção, é importante finalizar com alguns apontamentos sobre o percurso e o presente do grupo Ágora, em sua busca por analisar e compreender a produção de conhecimentos sobre significados e sentidos que temos atribuído ao processo educativo, visto como uma das práticas sociais que nos ajudam a problematizar os processos de relação sociedade e natureza.

Aproveitamos o momento final deste trabalho para reafirmar um princípio caro para o grupo de pesquisa: o debate de ideias, feito dialógica e democraticamente, princípio este que está traduzido na sua denominação Ágora, que provém do idioma grego ao se referir às praças públicas e às assembleias da polis. Esse princípio é evidenciado nos trabalhos desenvolvidos em parcerias estabelecidas ao longo das três décadas de existência: com a Rede EPEA, com o Programa de Cooperação entre a União Europeia e América Latina (ALFA), com o Rede Ambientalização Curricular dos Estudos Superiores (Rede ACES) e na revista Pesquisa em Educação Ambiental, cuja editoria é interinstitucional.

Dando continuidade ao que, historicamente, construiu e consolidou, tendo na Teoria Crítica o principal referencial teórico para os pesquisadores do grupo, temos nos movimentado em busca de novos conhecimentos e referenciais, articulando-nos tanto com grupos nacionais por meio do GT-22 da ANPEd, pela participação em eventos nacionais e internacionais, e em convênios firmados com outras universidades para intercâmbios, principalmente na América Latina.

O projeto Estado da Arte da Pesquisa em Educação Ambiental na América Latina (EArte $A L y C$ ), que envolve pesquisadores de diversos países da América Latina e Caribe, tem proporcionado a busca por novos referenciais teóricos, por novos procedimentos de análise, e o compartilhar de conhecimentos no campo da EA. Essa importante parceria tem início 
quando do encontro de pesquisadores no VIII EPEA, acontecido em 2015 no Rio de Janeiro, quando, em sessões de comunicação dos resultados dos trabalhos do grupo, colegas de países latino-americanos se entusiasmam com a proposta do Projeto EArte. A partir daí, foram muitas as oportunidades de trabalho conjunto, o que culminou com a iniciativa de formar o Colectivo de investigadores en Educación Ambiental Superior en América Latina y el Caribe (CIEASALyC). Em carta aberta o Coletivo afirma:

\begin{abstract}
La iniciativa de conformar un COLECTIVO surge de investigadores comprometidos con la temática en sus universidades de origen y con los territorios en que estas están involucradas, asumiendo que las problemáticas y los conflictos ambientales se agravan. Sin embargo, las instituciones de nivel superior de las que formamos parte, en muchos casos permanecen ajenas a la situación y hasta en ocasiones participan recibiendo fondos de megaemprendimientos que amenazan la sobrevivencia de los ecosistemas y las culturas que allí habitan.

[...] Consideramos fundamental, como COLECTIVO, reconocer que existen -no sin pugnas-visiones múltiples sobre la investigación, el conocimiento y las epistemologías, así como intereses e ideologías diversas que validan -también en tensión- el significado del/los conocimiento(s). Por esta razón resulta indispensable que los investigadores deban estar atentos y observar críticamente los procesos y tendencias de construcción y reconstrucción del campo de la investigación en EA. (CIEASALYC, 2019).
\end{abstract}

Os trabalhos, portanto, prosseguem, enfatizando o significado do processo educativo como prática social e as possibilidades e limites da Educação Ambiental como prática de construção de sociedades democráticas pautadas nos princípios da justiça socioambiental. As análises da produção do campo de pesquisa em EA denotam a centralidade da dimensão política tanto nas práticas pedagógicas quanto nas práticas de produção de conhecimentos no campo.

Em suma, a trajetória do grupo de pesquisa Ágora e sua atuação no campo da EA, trazendo discussões de natureza pedagógica, sociopolítica, além da discussão sobre a produção de sentidos em EA, articula-se a uma rede de produção de conhecimentos no campo da EA, com a participação de inúmeros pesquisadores nos mais diferentes lugares do Brasil e, inclusive, com as parcerias internacionais que progridem na medida em que o pensamento latino americano se faz conhecido, oferecendo caminhos alternativos e novas formas de pensar o mundo, um mundo ainda não inventado, livre da ameaça ecológica que coloca em risco a Vida no planeta. 


\section{Referências}

BAKHTIN, Mikhail Mikhailovich. O problema dos gêneros discursivos. In: Estética da criação verbal. Tradução Paulo Bezerra. São Paulo: Martins Fontes, 2003.

BONOTTO, Dalva Maria Bianchini; SANTANA, Luiz Carlos; CARVALHO, Luiz Marcelo de; CAVALARI, Rosa Maria Feiteiro. Grupo de Pesquisa "A temática ambiental e o processo educativo": concepções e práticas. Ambiente \& Educação, Rio Grande, v. 14, n. 2, p.123-130, 2009.

BRASIL. Lei n 9.795, de 27 de abril de 1999. Estabelece a Política Nacional de Educação Ambiental. Brasília: MMA, 1999. Disponível em:

<http://www.mma.gov.br/port/conama/legiabre.cfm?codlegi=321>. Acesso em: 23 jun. 2018.

CARVALHO, Isabel Cristina Moura. A pesquisa em educação ambiental: perspectivas e enfrentamentos. Pesquisa em Educação Ambiental, Rio Claro, v. 15, n. 1, p. 39-50, 2020.

CARVALHO, Isabel Cristina Moura et al. Educação Ambiental Crítica: nomes e endereçamentos da educação. In: Philippe Pomier Layrargues (coord.). Identidades da educação ambiental brasileira. Brasília: Ministério do Meio Ambiente, 2004. p. 13-24.

CARVALHO, Luiz Marcelo de. A Temática ambiental e o processo educativo: dimensões e abordagens. In: CINQUETTI, H. S.; LOGAREZZI, A. (Orgs.). Consumo e resíduos Fundamentos para o trabalho educativo. São Carlos: EdUFSCar, 2006. p. 19-27.

CARVALHO, Luiz Marcelo de. Pesquisa em Educação Ambiental no Brasil: um campo em construção? 2015. 455 fls. Tese (Livre-Docência em Educação) - Universidade Estadual Paulista Júlio de Mesquita Filho, Rio Claro, 2015.

CARVALHO, Luiz Marcelo de; et al. A educação ambiental no Brasil: análise da produção acadêmica - teses e dissertações. CNPq: Relatório Científico. Rio Claro, UNESP - Rio Claro, UNICAMP, USP - Ribeirão Preto, 2016.

COMISSÃO ORGANIZADORA. Perspectivas da Educação Ambiental no cenário brasileiro atual. In: ENCONTRO DE PESQUISA EM EDUCAÇÃO AMBIENTAL, 10, 2019, Aracajú. Anais. Aracaju: GEPEASE/UFS, 2019. s.p. Disponível em:

<http://epea.tmp.br/epea2019_anais/welcome/>. Acesso em: 30 ago. 2021.

LEFF, Enrique. Saber ambiental: sustentabilidade, racionalidade, complexidade e poder. Tradução de Lúcia Mathilde Endlich Orth. Petrópolis: Vozes, 2001.

LEFF, Enrique. Complexidade, Racionalidade Ambiental e Diálogo de Saberes. Educação \& Realidade, Porto Alegre, v. 34, n.3, p. 17-23, 2009. 
FERNANDES, José Artur Barroso (Org.). A avaliação da Década da Educação para o

Desenvolvimento Sustentável e perspectivas futuras. In: ENCONTRO PESQUISA EM

EDUCAÇÃO AMBIENTAL, 8, 2015, Rio de Janeiro. Anais... Rio de Janeiro:

UFRJ/UFRRJ/UNIRIO/FFCLRP-USP, 2017. s.p. Disponível em:

<http://epea.tmp.br/epea2015_anais/welcome/>. Acesso em: 30 ago. 2021.

FERNANDES, José Artur Barroso; PINTO, Vicente Paulo dos Santos; SOBRAL, Marcela de Marco (Orgs.). Políticas Públicas, Democracia e Práticas Educativas. In: ENCONTRO PESQUISA EM EDUCAÇÃO AMBIENTAL, 9, 2017, Juiz de Fora. Anais... Juiz de Fora: UFJF /UFF/ FFCLRPUSP, 2017. s.p. Disponível em: <http://epea.tmp.br/epea2017_anais/welcome/>. Acesso em: 30 ago. 2021.

MARQUES, Luiz. Capitalismo e colapso ambiental. Campinas: Editora Unicamp, 2015.

RAYMUNDO, Maria Henriqueta Andrade et al. (Orgs). Avaliação e monitoramento de políticas públicas de educação ambiental no Brasil: transição para sociedades sustentáveis [recurso eletrônico] Piracicaba: MH-Ambiente Natural, 2019. p. 21-54.

REVISTA PESQUISA EM EDUCAÇÃO AMBIENTAL - REVPEA. Sobre. Rio Claro: UNESP, s.d. Disponível em:

<https://www.periodicos.rc.biblioteca.unesp.br/index.php/pesquisa/about)>. Acesso em: 30 ago. 2021.

Submetido em: 30-08-2021.

Publicado em: 16-12-2021. 